\title{
Cloud-Enabled E-Governance Framework for Citizen Centric Services
}

\author{
Jara Muda1, Sisay Tumsa ${ }^{2}$, Amin Tuni², Durga Prasad Sharma ${ }^{3}$ \\ ${ }^{1}$ Bule Hora University, Bule Hora, Ethiopia \\ ${ }^{2}$ Arba Minch University, Arba Minch, Ethiopia \\ ${ }^{3}$ AMUIT MOEFDRE under UNDP \& Research Adviser, MAISM-RTU, Kota, India \\ Email: jaramudah123@gmail.com, sisay.tumsa@amu.edu.et, amint134@yahoo.com,dp.shiv08@gmail.com
}

How to cite this paper: Muda, J., Tumsa, S., Tuni, A. and Sharma, D.P. (2020) Cloud-Enabled E-Governance Framework for Citizen Centric Services. Journal of Computer and Communications, 8, 63-78. https://doi.org/10.4236/jcc.2020.87006

Received: May 25, 2020

Accepted: July 27, 2020

Published: July 30, 2020

Copyright (c) 2020 by author(s) and Scientific Research Publishing Inc. This work is licensed under the Creative Commons Attribution International License (CC BY 4.0).

http://creativecommons.org/licenses/by/4.0/

\begin{abstract}
In the modern arena, the Information and Communication Technologies (ICTs) have been playing a vital role in every walks of our day to day life. In order to enhance the ICT capacity and align with the global technology transformations, the developing countries have started introducing the computerization and automation processes at different levels of the governments. The several research studies revealed that the existing legacy of governance system and their services in current state have several issues and challenges in terms of timeliness, cost of services, delay in service delivery, time-bound availability of services (24/7/365), inefficiency services, ease of service and discomforts, poor service collaboration, absence of responsiveness, and limited security of sensitive information/documents. A significant question is still unanswered that how to bring the Citizens and Government bodies closer for alleviating the aforementioned issues and challenges of existing government system services. This research paper aims to investigate the issues and challenges in the current status of Governance and partial E-Governance systems which encompass the computerization or automation process. The research designs a cloud framework for effective delivery of citizen centric services in general and Ethiopia as a specific case study. After rigorous analysis of prior research efforts, along with primary survey and interview, it was clearly observed that cloud computing can be an alternative instrumental for significant transformation of governmental service delivery. The research paper used a mix of exploratory and constructive research design and methodology with qualitative \& quantitative data analysis approach. Finally, a Cloud Based E-Governance (CBEG) Framework is designed for the delivery of Ethiopian Citizen Centric Services. The validation, evaluation and acceptance test of the framework proves that the revealed knowledge can provide a significant transformation towards the betterment of the E Governance Services Delivery Systems.
\end{abstract}




\section{Keywords}

E-Governance, Framework, Cloud Computing, Citizen Centric, Hybrid Cloud

\section{Introduction}

Information and Communication Technologies (ICTs) in the modern arena have been playing a vital role in every walks of our day to day life and changing the way people act and perform their tasks. Every citizen of a given country needs SMART (Specific, Measurable, Available Real and Timely) systems and services from their Governing Systems. To enhance the effective delivery of up to date services and empower the citizens, the Governments have been rapidly shifting their Governance systems from manual systems to ICT enabled E-governance Systems. Hence, ICT can be used as a means to deliver effective and efficient governance services to the citizens and government bodies altogether. It's obvious that the E-governance is beyond the scope of e-government. While e-government is defined as an only delivery of government services using data or information to the public using electronic means. The e-governance allows citizen's direct participation in constituents or in political activities like Electronic democracy, Electronic voting, and participating in the political processes/events in online modes. The broader concept of the E-governance covers the government, citizens' participation, political parties and organizations, Parliament and the Judiciary functions [1] [2] [3] [4]. Therefore, the E-governance (Electronic Governance) can be defined as when the Governing body uses ICTs as a tool for delivering government services, exchange of information, communication, transactions, integration of various stand-alone systems and services between government-to-citizen (G2C), and government-to-business (G2B) services for the citizens for empowering them. According to a researches [2] [3] [5], Citizen-oriented governance is undoubtedly one of the most important considerations for governments all over the world. It is observed that most of the developing and developed countries have been focusing on the citizen-centric services over the network, i.e. called as e-governance. In the current era, citizen's desire is focused on the higher level of service or information access of the government services. The citizen wants to have direct interaction with the government through network media to minimize distance discomforts and get the services for 24 hours a day, 7 days a week and 365 days in a year. In E-Governance, Government can interact with its citizen easily and rapidly. There are a large number of e-governance services used by developing and developed countries facilitated by the various service providers in general. Among these, the main categories in Ethiopian context are Education, Employment, Policy, Health, Tax, Judicial/Legal System, and Agriculture. In the current state of art, the delivery of these services takes place through computerized or partially automated E-governance Services delivery Models. The major service delivery models in this domain of study are Government to Government (G2G), Government to Citizen (G2C) and Government to Business (G2B) 
in General and G2C, C2G Service Model in particular because, this study is an effort to Develop a Citizen-Centric Service E-Governance Framework in Ethiopian context where all the Services delivery models are proposed to be Integrated over E-Governance Portals and made available over Cloud infrastructural supported platforms. Since, E-governance ensures emerging ways to improve government services and make easy sharing of information and services to the citizens.

Due to the rapid advancement of ICT in the $21^{\text {st }}$ Century, Cloud Computing has emerged as an emerging umbrella technology which provides the opportunities and platforms for efficient design, development and deployment of E-Governance Systems. In general, these systems can lead to substantial cost, time and energy savings with great comfort. As a matter of fact, Cloud Computing can provide Hardware, Software, and Network, almost everything as an ICT service with improved performance of salient features/parameters. In general, the Cloud-Based E-Governance represents an emerging paradigm of distributed computing of E-Governance applications that utilizes services as a fundamental element in building an agile network of collaborating application distributed within and across governmental boundaries [3] [6] [7]. In 2010, Ministry of Communication and Information Technology (MCIT) of Ethiopia initiated to Migrate the Traditional (on-premise) model systems of its Governance to ICT enabled Modern Governance to serve the Citizens in providing fast and Real-time services in effective and efficient manners. As an initial observation, the MCIT observed that there was a scarcity of infrastructure and resource especially in the rural areas (as nearly $80 \%$ population of Ethiopia is living in rural area). But today the scenario has been changing rapidly. More and more people are getting to be technology savvy with access to internet in far flung rural areas. They are eager to access and utilize ICT enabled government services at their door. But in the current state of art practices, the lack of sequential flow of useful government information and services on Ethiopian government Portals (even though many services are hosted over portals but not unilaterally collaborated) is the biggest challenge. Also, there are critical challenges in timeliness of service delivery from Government to citizens or citizen to Government. In order to overcome all such aforementioned issues and challenges and to obtain the competitive advantage of the emerging technology paradigms like Cloud Computing, there is a strong need to investigate the Migration of the On-premise E-Governance services towards Cloud-Based E-Governance Services.

Therefore, this proposed migration framework can possibly be a new and smarter Convergence of Cloud \& Governance process for Re-Engineering of existing governance service process over Cloud. This may enable Ethiopian Citizens to enjoy the Government Services in anytime, anywhere over any device manners. In the study, efforts have been made to answer the following technical questions:

- What is the current status of Citizen Centric Government Services (Computerized Govt Services/semi-automated E-Governance) in Ethiopia?

- What are the characterized issues and challenges in Citizen Centric Govt. Services for bringing Citizens and Governmental closer towards mutual betterment? 
- How to design a most suitable E-Governance Services Delivery Framework for Ethiopian Citizen Centric Services?

\section{Related Work}

A research of Solomon D. Seifu et al. [8] discusses the adoption issues of cloud computing for Ethiopia Public and Private Enterprises, and the constraints in the current state of the art IT utilization in Ethiopian Enterprises. The paper discusses the alternative ways to solve the current IT utilizations limitations in Ethiopia Public and Private Enterprises. The researcher focused only on empirical analysis but didn't show any concrete plan to adopt and performance improvement indicators. The study revealed that Cloud Computing can be a better option for Information and Communication Technology (ICT) utilization in the developing country like Ethiopia, but the focus was confined only on the price of the package, hardware, and maintenance. Another study [9] investigated the way to provide economical and cost-efficient-Government services by adopting cloud Infrastructure as a Service design in developing economy of Ethiopia. This research could not reveal the reasons of selecting cloud-based Infrastructure as a Service (IaaS) among all. This study is a very shallow observation with small data set. Also, the researcher didn't clarify the delivery of public and mission critical i.e. high confidential data or information. The study also concluded with a superficial conclusion on adoption of cloud computing in E-Governance without any justification about cloud services and deployment strategy. A case study [10] demonstrated the different challenges faced in implementing e-Government activities. The opportunities to be gained are explored from the e-Government initiatives by considering the case of Ethiopia but the concept of Cloud computing is totally missed in this research. One of the related research works [11] indicated that the opportunity and challenge of E-governance in Ethiopia, have significant impact on public administration specifically on the services provided by E-governance of Ethiopia called Toll free 888 call center. Additionally, the Author reveals that the call center \& e-government portal of Ethiopia is still lagging behind in utilizing information and communication technologies for delivering government services online. In the recent years, many researchers have been witnessed significant importance of Cloud Computing technology in the government agencies for the most feasible use in computing, communication and collaboration and how helpful it is to extend the Government services to the rural population easily. It's known that the 80 percent of the population of Ethiopia lives in the rural areas. In rural areas, the scarcity of infrastructure and resource may hinder citizen to get timely information. This implies that the Cloud Computing Technology, which contains all resources and infrastructure with promised high uptime and timely delivery can support these services in effective and efficient manners.

A study of Pusp Raj Joshi, et al. [12] is related with the proposed study as the main aim of researcher is to develop a framework for G2G cloud-based e-government service for developing country. But the study was focused only on the gov- 
ernment to intergovernmental service model. Citizen centric service delivery over cloud is not covered. Also, the framework does not cover any specific service and deployment model or strategy for different kinds of citizen centric information delivery. The study focuses only in Indian governance context. In a paper [13] the researchers tried to explore the possible usage of cloud in E-governance processes but failed develop any Framework to show how the E-governance services will be mapped over cloud in the sense of real world scenarios. Also, the characters/features covered in this research study are limited like scalability, reliability and performance and the cost only. The researcher enlisted only enlisted few of the merits and challenges but didn't collect the primary data/facts about ground reality using different kinds of fact-finding techniques like survey (questionnaire), interview (questionnaire) and technical observation (check list). Also, this study focuses on Indian governance perspective only. The research [14] is somewhat similar with the proposed study. The proposed study adopts and explores the conceptualized framework with additional features/chars in contextualized and localized perspective and challenges. This study also focuses the Indian governance features, practices and the perspective. However Ethiopian context is totally different in terms of governance process and infrastructure viability.

After primary observation and review of salient related research studies/reports in localized context, the researcher observed a strong need to study and analyze the current state of the art electronic or digital governance practices in Ethiopia. The rigorous analysis of relevant researches clearly indicated that there is an acute shortage and knowledge gap in the Governance or E-Governance systems in developing vs. developed countries. In the localized context, there is a clear-cut lack of research studies. This motivates the study to collect the facts through survey of citizens, interview of professionals and experts and technical observation of the researcher self. This process can reveal the ground reality for designing a most feasible Framework for Ethiopia Citizen-Centric Services. This framework can help in getting Up-to-date and timely services in anytime, anywhere over any device manners. These situations indicate that there is no communication and collaboration and among the services over existing Portals for computing in governance processes. This needs a systematic scientific investigation for the solution to fully design, develop and deploy in the country.

\section{Research Design and Methodology}

\subsection{Research Design and Approach}

This study by nature is mixed type of exploratory cum constructive research. Initially, the study starts from the investigation of the performance and features of the existing Governance or E Governance systems in place. Later the gaps between Current E-Government system and the Cloud-enabled E-Governance systems are identified to explore the adoption possibilities of cloud in Governance processes of Ethiopia. Finally, the research paper constructed a framework for governance process transformation over cloud i.e. E-Governance Framework over Cloud and hence this study is exploratory cum constructive. 
The researchers selected Mixed approach or methods because, to collect the most important and relevant facts from the respondents (target population and eligible to provide detailed answers) in the research study problem domain.

\subsection{Sampling Methods and Size}

This study used a purposive sampling method. For the primary data collection, the Ethiopia Ministry of Innovation and Technology, and Residential Citizen of Ethiopia were selected for data sample to understand and analyze the existing state of art governance and e-governance systems along with issues and challenges. The purposive sampling is a form of non-probability sampling in which researchers rely on their own judgment when choosing elements of the population to participate in their study.

From the Seventy (70) population's total size only fifteen/experts and staffs, and forty-two Citizens responded. Therefore, total sample size for this research study was Fifty-Seven (57) and data was collected via cloud enabled Google Form survey tool. Since the research study is moreover scientific and applied and therefore Fifty-Seven sample size is sufficiently representative for the identification of problems and research gapes towards generalization.

\subsection{Data Collection Methods for the Proposed Research Study}

As illustrated in Figure 1, there are two main categories of data collection methods which are numbered as: 1) Primary data collection and 2) Secondary data

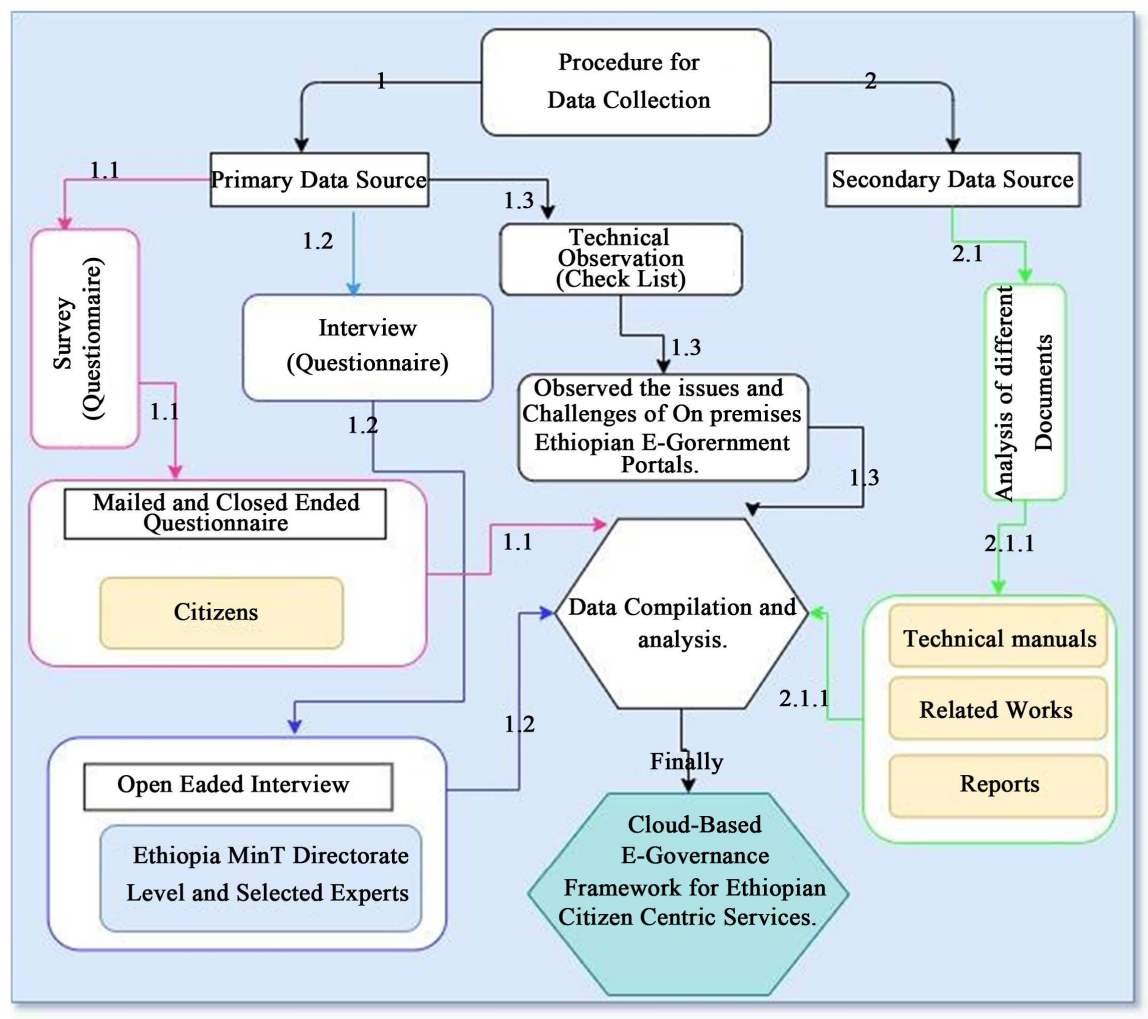

Figure 1. Summary for the data collection/gathering methods. 
collection). Each categories or classification of Data collection methods has its own sub categories like 1.1, 1.2 and 1.3 for primary and 2.1 for secondary data collection respectively.

In this research paper, the primary and secondary data collection from salient sources was done using the suitability assessment of data collection tools presented in Figure 1 like: 1) Survey questionnaire for primary data collection from the users or low level stakeholders, 2) Interview questionnaire for primary data collection from experts and domain specific professionals, and 3) Check List for researcher's own observation about the domain specific issues and challenges. The secondary data was collected from salient sources to understand and justify the research gapes. The sources used were technical reports, related research works, white papers, and technical reports.

\section{Data Analysis and Discussion}

In the data collection process open-ended interview (questionnaire), survey (questionnaire) and technical observations (Check List) were used. The parameters considered in this research paper were: 1) Awareness, 2) Cost \& Time, 3) Anytime, Anywhere Accessibility, 4) Service Delivery at Door, 5) Availability (24/7/365), 6) Responsiveness \& Performance, 7) Reliability with security \& privacy, 8) Upto-date Information Delivery, and 9) Service Collaboration \& Interoperability.

The analysis of the primary facts collected from the salient sources using Survey, Interview and Observations are as follows:

\subsection{Awareness towards Cloud Computing Technology?}

In the data collection process, Experts and Staffs of the high-level Directorates of E-Government and ICT capacity building, Ministry of Innovation and Technology (MinT), participated in survey and interview. They were asked the questions for assessing the level of awareness about cloud computing in E-Governance. Their responses, as presented in Figure 2 revealed that maximum i.e. $86.1 \%$ respondents are aware about cloud technologies and out of them $81 \%$ are using cloud services like (Gmail, Dropbox, One Drive, office 365 and etc.) in trusted manner to get the benefits of cloud technologies. They clearly indicated that they
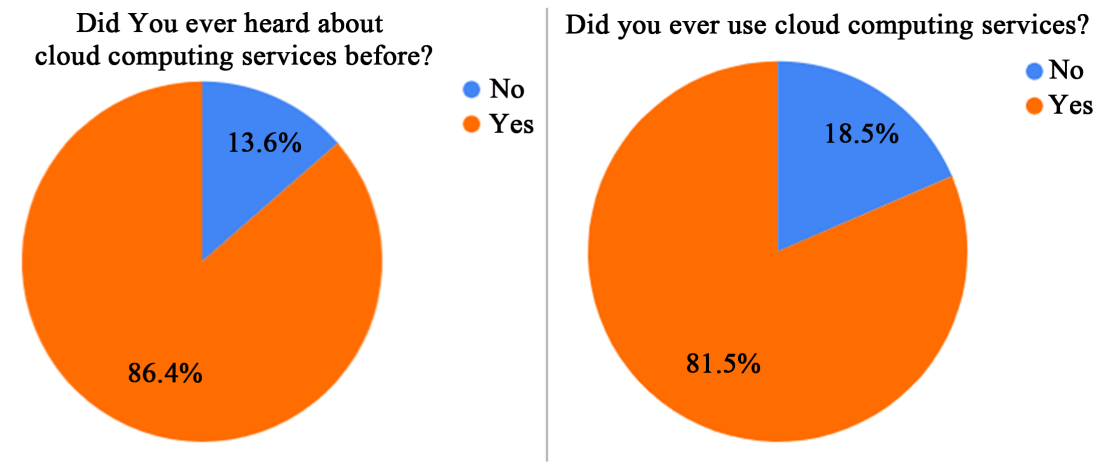

Figure 2. Users awareness' toward cloud computing technology. 
are interested to adopt an alternative solution for Ethiopian E-Governance Systems so as to modernize and upgrade the existing technology infrastructure services with enhanced performance of the existing E-Services. This scenario implies that Ethiopia has adequate awareness about cloud technology and migration of E-Governance over cloud can be a great promising shift. Using the same parameters, the professional interview and technical observation also revealed the same and verified through the secondary source's analysis [15] [16] [17].

\subsection{Cost and Time Effectiveness with Low Maintenance}

When delivering contemporary IT solutions, Cost Optimization is assumed as one of the most important and complex elements. The ICT services over the cloud are being offered using pay per use model. In this, the resources are pooled for the usage of the multiple tenants, so it leads to optimal usage of resources which justifies effectiveness of the costs. This feature was also clearly accepted when enquired and interviewed to the target population elements, and professional experts.

The respondents' response clearly justified that the cost of transportation is also one of the major issues in the existing e-governmental service delivery models and they need an alternative solution. As presented in Figure 3, the highest (75.4\%) part of the respondents agreed that that governmental services and the transportation cost in the current systems are very high and they will be pleased to adopt a new and cost-effective solution like cloud.

\subsection{Anytime, Anywhere Accessibility of Service}

This was feature of the cloud was also clearly accepted when enquired and interviewed to the target population elements, and professional experts. Here the Governmental sectors can select a Cloud service provider without any up-front and hidden costs to facilitate anytime, anywhere over anywhere device services.

The Survey and Interview inputs clearly revealed that the existing Ethiopian Governance system, like E-Services portal accessibility, is very poor. Of course, they can be accessed from anywhere and anytime but only the web-based systems of services with real time internet connectivity. Most often the time, the services are down and it was verified during technical observation and interview of professionals. The existing manual governance systems work only 5 days in a week for 8 hours per day only and are not user friendly and easy to use. Therefore, as presented in Figure 4, the maximum (71.9\%) responses of the respondents revealed that they need an urgent improvement in E-Governance service delivery systems so that the services can be accessed at anytime, anywhere using any type of computing devices like mobiles, laptops, desktops or tablets. The $24.6 \%$ of respondents' response indicated that there is a typical kind of digital divide (haves and have nots) in the countryside.

\subsection{Service Delivery at the Door to the Citizens}

As per the facts collected through interview, survey and technical observations, it was revealed that the existing e-government service portals have longer duration 
If your answer to question number 7 above is "No" what are the challenges do you think so? Please tick all that is could be the answer

57 responses

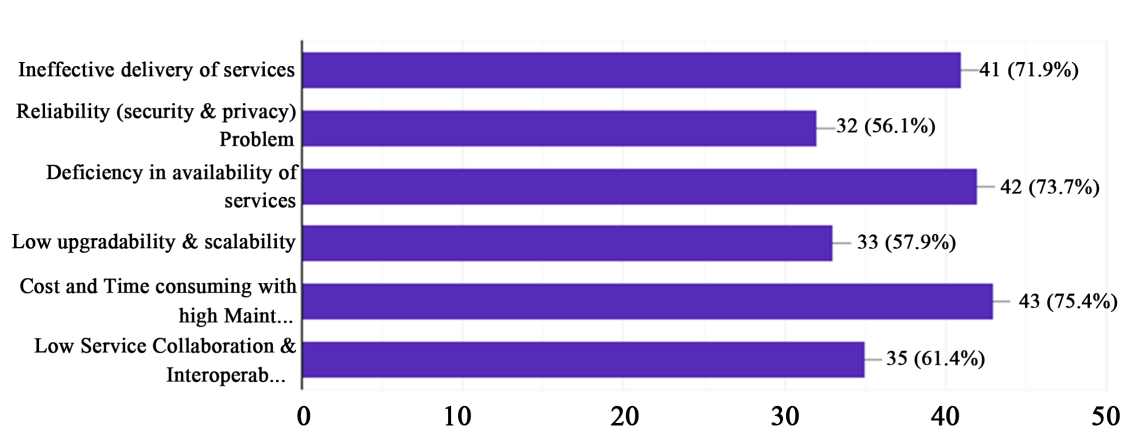

Figure 3. Existing Ethiopia e-government challenges.

If the answer for the Q\#5 above is NO, do you think that there is a strong need for a government services delivery system that serve all the time and everywhere from any devices?

57 responses

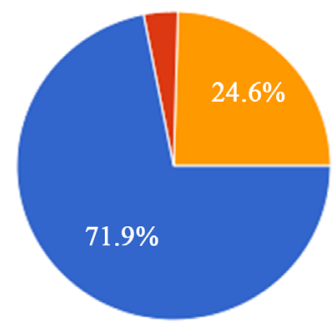

- Yes

No

Maybe

I Don't Know

Figure 4. Strong need towards anytime, anywhere accessibility.

for service delivery to citizens, and lack of efficiency in rectifying citizen's complaints (if any). It was observed that the Citizens have to travel long distances to get the services needed, which results into wastage of time (especially citizens from the far-flung areas). Therefore, as presented in Figure 3, the maximum i.e. $71.9 \%$ of the respondents accepted that there is no any service provided by the Govt at the door of the citizen in the current Ethiopian Governance and e-government systems. This implies that the majority of the people are not pleased and they need an alternative system with effective service delivery at their doors.

\subsection{Availability $(24 / 7 / 365)$}

The important objective of the citizen centric solutions is to make the services all the times means high availability. If the e-Governance portals are designed in a way that every system is integrated with every other system of the different government departments with features and facilities like replication, and high fault tolerance then the services can be said to be available in 24/7/365 manner. These systems can reduce the waiting and wastage of time. During the fact-finding process using technical observation (check list), survey (questionnaire), and interview. 
The maximum i.e. $91.2 \%$ of the respondents as mentioned in Figure 5 accepted that there is lack of high availability of governmental service in the current state of art models and they want an alternative system.

The fact-finding responses clearly indicated that in case of power failure, the services totally interrupt because the data center/servers have no alternative Replica of the Server in Ethiopian E-Service deployment models. This implies a question mark on the high availability of the services. From this point of view, this research study states that an alternative solution is needed to ensure the high-end Availability of E-Government Services.

\subsection{Responsiveness and End User Satisfaction}

As responded by the respondents during interview and survey with cross verification through researcher's observation, the maximum i.e. $77.2 \%$ of the respondents accepted that they are not satisfied with the services provided over Ethiopian E-Government portals and presented in Figure 6. This was also verified through technical observation and justified by the secondary source studies. This research input clearly states that an alternative solution is again expected for assurance of high responsiveness from the Government Services.

Do you think that the access to government support services are available anytime, anywhere manner?

$$
57 \text { responses }
$$

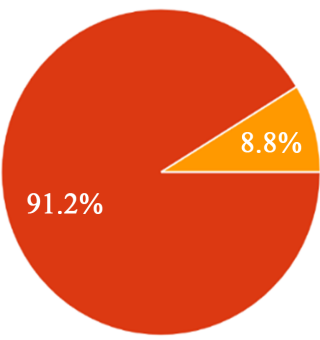

$$
\begin{aligned}
& \text { Yes } \\
& \text { No } \\
& \text { Maybe }
\end{aligned}
$$

Figure 5. Availability of service in existing e-government.

Do you think that you are satisfied on the services provided to you on E-Government portal?

57 responses

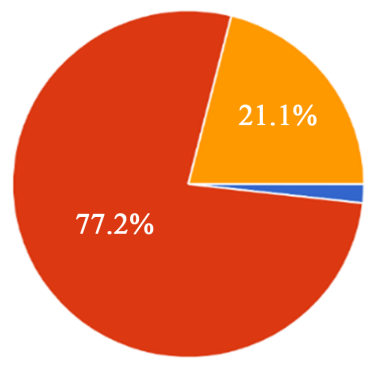

Figure 6. End user satisfaction on the existing services. 


\subsection{Reliability of the E-Governance System Services}

The researchers also tried to assess the reliability or the level of trust of the citizens on the online services provided by the governance and E-Government portals. The interview, technical observation and survey clearly revealed that $56.1 \%$ of the respondents are agree to accept the reliability issues in the existing Ethiopian e-government portals as presented in Figure 3. The Citizens whom the researchers approached interviewed and surveyed are interested in alternative technological solution which can ensure the citizens to get high reliable access to the services from any location in convenient manner.

\subsection{Up to Date Services and Scalability}

During the technical observation of the researcher and the interview of selected stakeholders/professionals, it was clearly verified that the services hosted over Ethiopian E-Government portals are not up to date. Most of the services are out dated and useless. The respondents' responses states that $57.9 \%$ of the respondents are agree to accept that the services on existing e-government portals are outdated or not up to date as mentioned in Figure 3.

\subsection{Collaboration and Interoperability among Various Services}

Till date, Ethiopia has 20 ministries. All the ministries have their own services for the citizens [18]. These ministries are geographically located in different location of the capital city. It is observed that there is no single point of access or availability of Citizen Centric Services. They want a single window service delivery system (i.e. in the current state there is no collaboration amongst the various citizen centric services over a single system for unified integration and interoperability). This results in to a wastage of time and cost of the citizens to get the services at different locations. Specially, citizens from far flung area also need to travel long distances as the departments are established in different corners of the city or town of the capitals or city admin locations. During fact finding techniques using interview, technical observation and survey, the maximum i.e. $61.4 \%$ of the respondents accepted that there is a lack of unified integration and interoperability among the systems designed for the various Ethiopian Governmental services as mentioned in Figure 3.

In order to collect the facts about the final solution that can alleviate the aforementioned issues and challenges, the maximum i.e. $80.7 \%$ of the respondents accepted that an alternative governmental service delivery solution like cloud enabled e-governance framework can alleviate all such aforementioned issues and challenges. The only $10.5 \%$ of respondent accepted that may be if there are technologies better than that of currently in use or cloud and mentioned in Figure 7.

\section{The Cloud-Based E-Governance Framework for the Ethiopian Citizen Centric Services}

After detailed feature-based analysis and suitability assessment of the Cloud Computing Service and Deployment Models; the mix version of SaaS, PaaS, and IaaS 
Do you want an alternative government service delivery solution to overcome such challenges encountered by existing Ethiopian E-Government Service delivery system?

57 responses

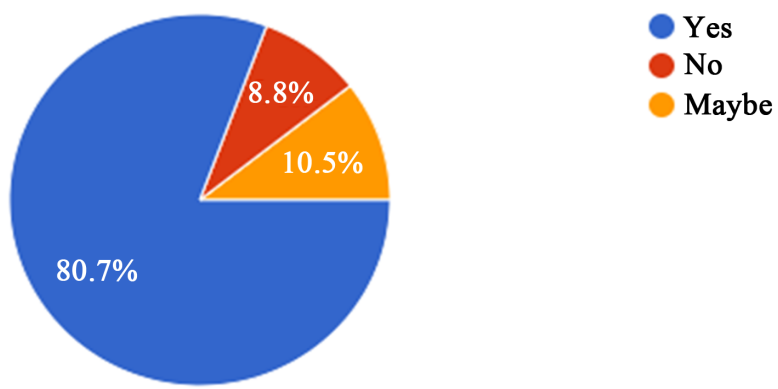

Figure 7. The need to have emerging technology as a solution.

along with Hybrid Cloud Deployment model were selected for the Proposed Framework and its functional demonstration. The proposed framework is the combination of five different tiers: 1) Citizens Tier, 2) SaaS Tier, 3) PaaS Tier, 4) IaaS Tier, and 5) E-Governance Tier. Figure 8 presents the proposed Cloud based E-Governance Framework for Ethiopian Citizen Centric Services.

In the proposed Framework, the Citizen Tier presents or contains the Ethiopian citizens i.e. the principal beneficiaries of the Framework. The SaaS tier (presentation layer) contains the several types of E-Governance applications for the citizens/end-users to get the services from the framework-based system. The applications or software are proposed to be developed/customized at PaaS tier. In this tier, various cloud-based government websites/portals/applications can be developed and deployed. The PaaS Tier contains all the necessary development tools/platforms that can be used or rented from CSPs based on Pay per use model.

In between the PaaS and SaaS tiers, there is a cloud firewall. This firewall is deployed in proposed framework for filtering or scanning the traffic so as to avoid the possibility of malicious practices or attacks. This security layer i.e. firewall is deployed for ensuring the security, privacy, confidentiality and reliability of the citizen centric services from unwanted intruders' entry or attacks. Since all the government services are either Private (government related sensitive services) or Public (citizen centric services), so to protect these from unauthorized individuals and unauthenticated parties, CSPs implement firewalls which are significantly more advantageous. These firewalls and other security and surveillance systems are regularly updated, administered and monitored by the high-end professionals for the security, reliability and quality assurances under SLA. It can be provided to the cloud user as a fermium or premium service (security as service). These services over the cloud create a virtual barrier between trusted cloud and untrusted internet traffic. This Cloud Firewall Feature makes the designed and developed framework a unique entity. 


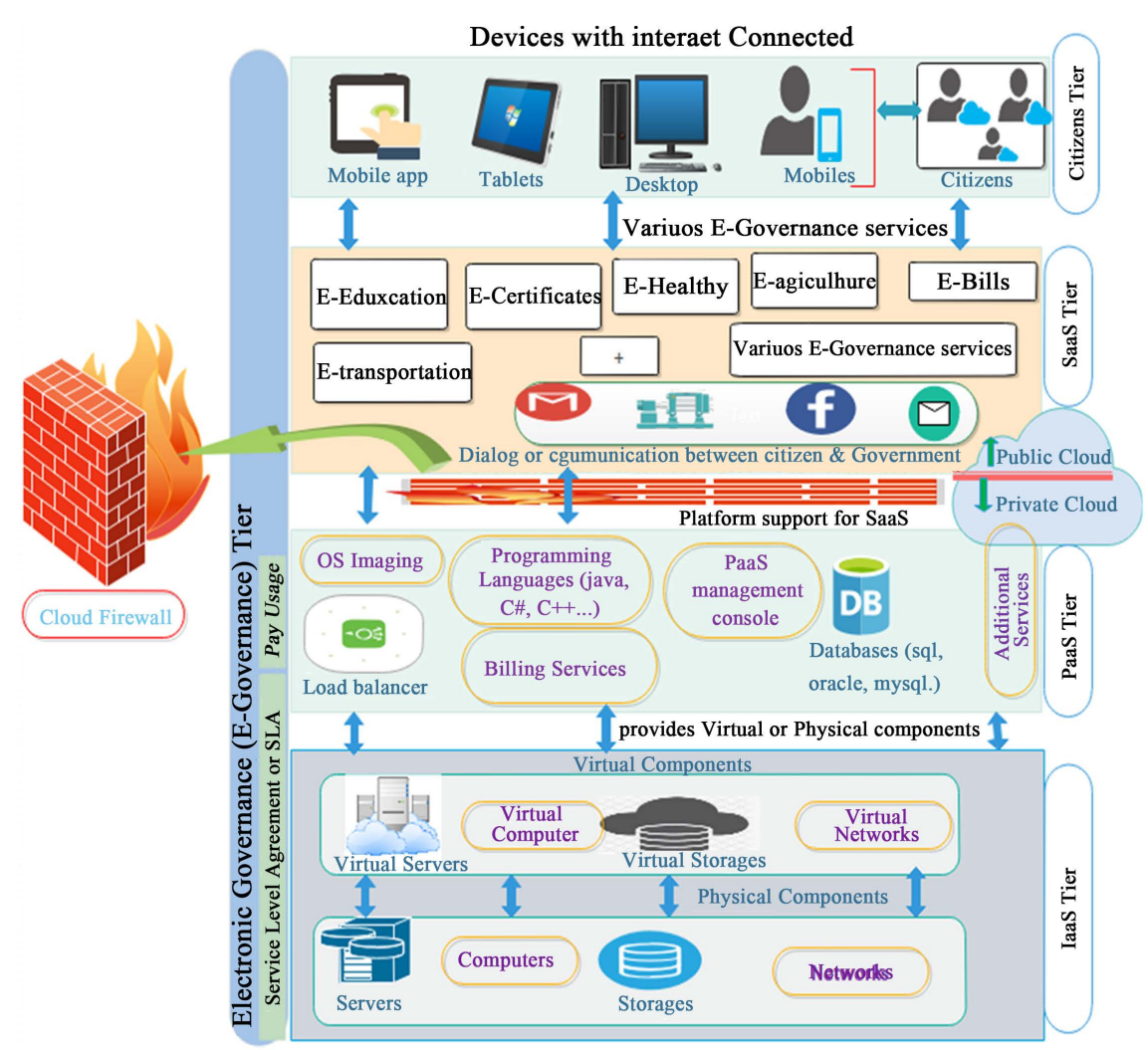

Figure 8. Cloud based e-governance framework for Ethiopian citizen centric services.

The IaaS tier is the fourth tier in the proposed framework. This tier comprises of the Infrastructure (both virtual and physical) needed for the SaaS \& PaaS tiers. The final tier in the proposed framework is E-Governance Tier which is the composition of all the four tiers (Citizens Tier, SaaS Tier, PaaS Tier and IaaS Tier).

The proposed framework has a great advantage in multi-dimensions like: when the citizen services may successfully migrate to cloud computing platform, there is no worries about Storage space. And also, time, cost and labor force of citizen can be minimized. The service can be made available for citizen anytime, anywhere over any device. So, these are the few advantages (pros) of New proposed framework.

\section{The User Evaluation and Acceptance of the Framework}

As presented in Figure 9, the qualitative evaluation and user acceptance test of the framework was done in which salient citizens (end users or stakeholders) participated. The evaluation and acceptance inputs collected from these stakeholders clearly indicate that the cloud-enabled e-governance services delivery framework based system can be selectively better and enhanced than the existing manual, semi computerized or web based automated systems for the efficient and effective delivery of the citizens centric services in governance service delivery than that of the existing or on-premises governance and e-governance service delivery systems. 
End users acceptance assessment for Existing \& DPS-JM Framework

घ Existing EGS $\backsim$ Cloud-Based EGS

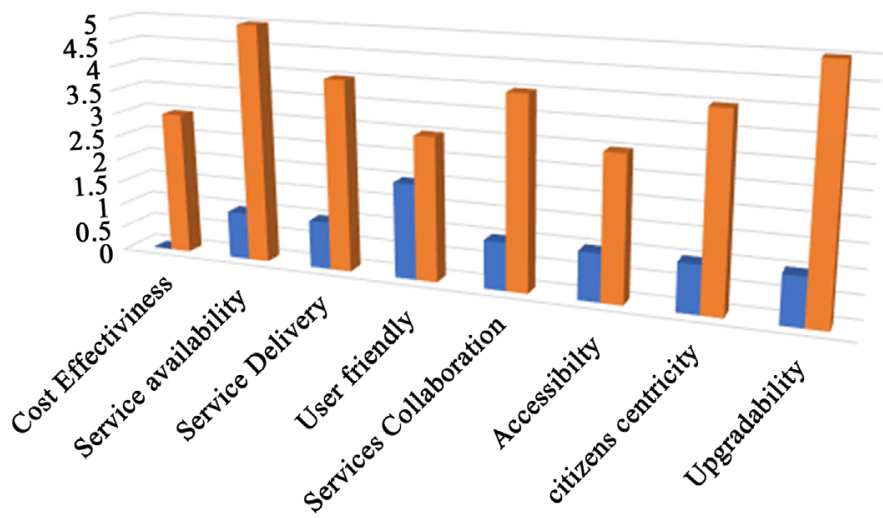

Figure 9. Acceptance and evaluation of the framework.

The acceptance and evaluation test of the framework and its prototype revealed that $60 \%$ of the stakeholders agreed with cost effectiveness, $90 \%$ agreed with services availability, $80 \%$ agreed with services delivery, $60 \%$ agreed with user's friendliness, $80 \%$ agreed with services collaborations, 60\% agreed with accessibility, $80 \%$ agreed with citizens centricity and $90 \%$ agreed with services upgradability. This implied that the CBEG Framework is an innovative and significantly new transformation framework towards the next generation shift and transformation of the E Governance Services in developing countries like Ethiopia.

\section{Conclusions and Recommendation}

\subsection{Conclusions}

In this research paper, the existing issues and challenges were investigated in the current state of art systems (computerized/automated) used for Ethiopian Governance or E-Government Services. These issues and challenges are carefully investigated and analyzed with different parameters-based perspectives. The parameters (feature) based analysis of the primary and secondary data clearly revealed that a cloud-based E-Governance framework for Ethiopian citizen Centric Services (CBEG) can be a better and next generation transformation or shift baselines for the Ethiopian citizen Centric Services. Before designing the cloud-based E-Governance Framework for Ethiopian Citizen Centric Services, the study examined and observed different Services over Existing Ethiopian National Datacenter. The proposed framework as presented in Figure 8, is the combination of five different tiers 1) Citizens Tier, 2) SaaS Tier, 3) PaaS Tier, 4) IaaS Tier and 5) E-Governance Tier.

The designed, and developed CBEG Framework for Ethiopian Citizen Centric Services is the major contribution of this research and it can be used as a baseline to transform or shift towards next generation E-governance service delivery in Ethiopia over cloud for effective and efficient computing, communication and collaborations. 
Since Cloud computing technology is an emerging technology, there is scarcity of materials that clearly explain the technical aspect. The absence of powerful machines or fully fledged cloud platform for the implementation of the framework to explore the fullest potential is also another limitation. The scarcity of tangible and intangible resources, such as time and budget that may help in exploring the technology deeply and sufficiently, is another limitation.

\subsection{Recommendation}

In this research study, the researchers tried to cover several parameters and investigated for the enhancements to meet the objectives of this study. However, the following list of activities is considered as a future work for further studies:

1) This research study didn't cover direct payment to CSPs. The reason is that as Ethiopian policies don't allow the online payment Gateways for individuals, selecting the External CSPs like IBM, Google Cloud, AWS, Microsoft Azure, or Oracle and they are only allowed for the organizations having license not for individuals.

2) Again, the researchers recommend that re-designing and developing a fully-featured cloud based E-Governance framework for Ethiopian Citizen Centric Services and integrating all Services (E-Services) towards Sharing of experiences, Computing, Communication and Collaborating Resources can be another fold of new knowledge research.

\section{Conflicts of Interest}

The authors declare no conflict of interest regarding the publication of this paper.

\section{References}

[1] Fang, Z.Y. (2002) E-Government in Digital Era: Concept, Practice, and Development. International Journal of the Computer, the Internet and Management, 10, 1-22.

[2] Sharma, D.P. and Shekhawat, H.S. (2012) Hybrid Cloud Computing in e-Governance: Related Security Risks and Solutions. Research Journal of Information Technology, 4, 1-6.

[3] Sharma, D.P. and Tilahun, T. (2015) Design and Development of E-Governance Model for Service Quality Enhancement. Journal of Data Science and Information Processing, 3, 55-62. https://doi.org/10.4236/jdaip.2015.33007

[4] Sharma, D.P. and Shekhawat, N.S. (2011) Cloud Computing Security through Cryptography for Banking Sector. Proceedings of the 5th National Conference on Computing for National Development, New Delhi, 10-11 March 2011, 1-3.

[5] Asres, K., Gure, A.T. and Sharma, D.P. (2020) Automatic Surveillance and Control System Framework-DPS-KA-AT for Alleviating Disruptions of Social Media in Higher Learning Institutions. Journal of Computer and Communications, 7, 1-15. https://doi.org/10.4236/jcc.2020.81001

[6] Smitha, K.K., et al. (2012) Cloud Based E-Governance System: A Survey. Procedia Engineering, 38, 3816-3823. https://doi.org/10.1016/j.proeng.2012.06.437 
[7] Sharma, D.P., Tadesse, T. and Tuni, A. (2018) A Unified Strategic Model for Isolated Systems Integration. International Journal of Information Technology \& Computer Sciences Perspectives, 7, 33-43.

[8] Demmisie, S., et al. (2017) Cloud-Computing: Adoption Issues for Ethiopian Public and Private Enterprises. Electronic Journal of Information Systems in Developing Countries, 7, 1-14.

[9] Itana, T. and Omer, A.M. (2016) Adopting Cloud IaaS Architecture for Ethiopian e-Government Services. HiLCoE Journal of Computer Science and Technology, 2, No. 1.

[10] Belachew, M. (2010) E-Government Initiative Case of Ethiopia. In: Davies, J. and Janowski, T., Eds., Proceedings of the 4 th International Conference on Theory and Practice of Electronic Governance, ACM, New York, 49-54.

https://doi.org/10.1145/1930321.1930332

[11] Alemayehu, A. (2013) The Opportunities and Challenges of E-Governance in Ethiopia and Its Significant Impact on Public Administration. International Journal of Advanced Research in Computer Science and Software Engineering.

[12] Joshi, P.R. (2017) A Framework for Cloud Based E-Government from the Perspective of Developing Countries. Journal of Future Internet, 9, 80.

https://doi.org/10.3390/fi9040080

[13] Dash, S. and Kumar, S. (2016) E-Governance Paradigm Using Cloud Infrastructure: Benefits and Challenges. Procedia Computer Science, 85, 843-855.

https://doi.org/10.1016/j.procs.2016.05.274

[14] Tewari, N. and Sharma, M.K. (2014) Conceptual Framework for Cloud Supported E-Governance Services. IOSR Journal of Computer Engineering, 16, 134-145. https://doi.org/10.9790/0661-1618134145

[15] Kassahun, A. and Sharma, D.P. (2016) Suitability Analytics and Cloud Computing Adoption Modelling for Educational Institutions. International Journal of Information Technology \& Computer Sciences Perspectives, 2121-2127.

[16] Yadav, D., Sharma, D.P. and Keswani, B. (2017) A Study of Intranet over Cloud. International Journal of Innovations in Engineering and Technology, 7, No. 2.

[17] Sharma, D.P. and Singh, N. (2013) Banking Security Implementation through Cloud Computing. Proceedings of the 7 th National Conference, INDIACom-2013, New Delhi, 7-8 March 2013.

[18] Standards, A. (2018) Addis Standards. http://addisstandard.com/news-update-pm-abiy-ahmeds-downsized-cabinet-sees-5 0-per-cent-women-ministers-assume-key-positions 